\title{
Author Correction: Molecular estimation of neurodegeneration pseudotime in older brains
}

\author{
Sumit Mukherjee (D), Laura Heath, Christoph Preuss, Suman Jayadev, Gwenn A. Garden, Anna K. Greenwood, \\ Solveig K. Sieberts (D, Philip L. De Jager (D), Nilüfer Ertekin-Taner, Gregory W. Carter (D, Lara M. Mangravite \& \\ Benjamin A. Logsdon (1)
}

Correction to: Nature Communications https://doi.org/10.1038/s41467-020-19622-y, published online 13 November 2020.

In the original version of this Article, the Data Availability statement was incomplete. The following text has been added to the Data Availability statement: 'The data described in this manuscript are available via the AD Knowledge Portal (https://adknowledgeportal. org). The AD Knowledge Portal is a platform for accessing data, analyses, and tools generated by the Accelerating Medicines Partnership (AMP-AD) Target Discovery Program and other National Institute on Aging (NIA)-supported programs to enable open-science practices and accelerate translational learning. The data, analyses, and tools are shared early in the research cycle without a publication embargo on secondary use. Data are available for general research use according to the following requirements for data access and data attribution (https://adknowledgeportal.synapse.org/DataAccess/Instructions). See: https://doi.org/10.7303/syn23262875.'

Published online: 03 December 2020

\footnotetext{
(c) (i) Open Access This article is licensed under a Creative Commons Attribution 4.0 International License, which permits use, sharing, adaptation, distribution and reproduction in any medium or format, as long as you give appropriate credit to the original author(s) and the source, provide a link to the Creative Commons license, and indicate if changes were made. The images or other third party material in this article are included in the article's Creative Commons license, unless indicated otherwise in a credit line to the material. If material is not included in the article's Creative Commons license and your intended use is not permitted by statutory regulation or exceeds the permitted use, you will need to obtain permission directly from the copyright holder. To view a copy of this license, visit http://creativecommons.org/licenses/by/4.0/.
}

(C) The Author(s) 2020 